\title{
Primary Mediastinal Lymphoma Revealed By Cardiac Tamponade
}

\author{
El Boussaadani Badre, MD*, Chakib Benajiba, MD, Hajar Ourtassi, MD, Cherti Mohamed, MD
}

Department of Cardiology B, CHU Ibn Sina, Rabat, Morocco

DOI: $10.36347 /$ sjmcr.2020.v08i03.025

| Received: 24.02.2020 | Accepted: 09.03.2020 | Published: 18.03.2020

*Corresponding author: El Boussaadani Badre

\section{Abstract}

Primary mediastinal large B-cell lymphoma (PMBCL) is a distinct entity within B-cell lymphomas (2-4\% of nonHodgkin lymphomas). It occurs most frequently in young females but rarely during pregnancy. Moreover, a cardiac tamponade is unusually found in pregnant women. We describe a case of a 32-year-old woman, 16-week pregnant, with cardiac tamponade revealing PMBCL, where urgent pericardiocentesis was required to maintain maternal cardiac function. An MRI (Magnetic Resonance Imaging) revealed a huge mediastinal mass of which biopsy confirmed the diagnosis of a PMBCL. A spectacular improvement of the clinical signs was obtained after a first line chemotherapy including rituximab, cyclophosphamide, doxorubicin, vincristine, and prednisone (R-CHOP). Our patient received the entire chemotherapy during her pregnancy with a regular multidisciplinary follow up. PMBCL can expose pregnant women to cardiac tamponade, and physicians should be aware of this complication mainly when pericardiocentesis is necessary.

Keywords: B-cell lymphoma, tamponade, chemotherapy.

Copyright @ 2020: This is an open-access article distributed under the terms of the Creative Commons Attribution license which permits unrestricted use, distribution, and reproduction in any medium for non-commercial use (NonCommercial, or CC-BY-NC) provided the original author and source are credited.

\section{INTRODUCTION}

Primary mediastinal B cell lymphoma (PMBCL) has been recognized as a subtype of diffuse large $B$ cell lymphoma (DLBCL) based on its distinctive clinical and morphological features. Many diagnosed patients present the lymphoma in the mediastinum only, but the tumor can extend locally to involve other thoracic structures. Although PMBCL frequently spreads locally from the thymus into the pleura or pericardium, it rarely causes tamponade and is uncommonly found during pregnancy.

\section{CASE REPORT}

A 32-year-old woman, 16-week pregnant, with no medical history nor cardiovascular risk factors, presented to the emergency department with shortness of breath, orthopnea, hemodynamic instability with low systolic blood pressure, tachycardia, pulsus paradoxus and left pleural effusion syndrome. ECG showed a low QRS voltage with electrical alternans and sinus tachycardia (Figure-1). Chest $\mathrm{X}$ ray revealed a "whiteout" of the lung (Figure-2). Echocardiography performed immediately showed a circumferential pericardial effusion of great abundance with a "swinging heart" aspect, measuring $30 \mathrm{~mm}$ along the apex and $26 \mathrm{~mm}$ along the lateral wall of the right ventricle with intermittent collapse of the right atrium and sign of cardiac tamponade (Figure-3).

The patient was initially treated with intravenous fluids and inotropic agents. Then, a "Blind" pericardiocentesis was performed but with unsuccessful clinical result. Thus, an echocardiography-guided pericardiocentesis was required, which allowed the outpouring of a total of $1500 \mathrm{~mL}$ of citrine-yellow fluid over 72 hours. Repeated echocardiograms did not reveal any reaccumulation of pericardial fluid afterwards, the pigtail catheter was then removed from the pericardial cavity. An MRI (Magnetic Resonance Imaging) performed later showed a large anterior mediastinal mass with several relationships to surrounding structures (pulmonary parenchyma, aorta, digestive axis), accessible for biopsy.

The latter combined with anatomopathological study demonstrated a morphological and immunohistochemical profile of Primary mediastinal large B-cell lymphoma associated with interstitial fibrosis. The patient was referred to the department of Hematology for a complementary treatment.

A spectacular improvement of clinical signs was obtained after a first line chemotherapy including rituximab, cyclophosphamide, doxorubicin, vincristine, 
and prednisone (R-CHOP). Fetal ultrasound did not reveal evidence of structural or functional anomalies as the fetus did not show any developmental delays or physical abnormalities.

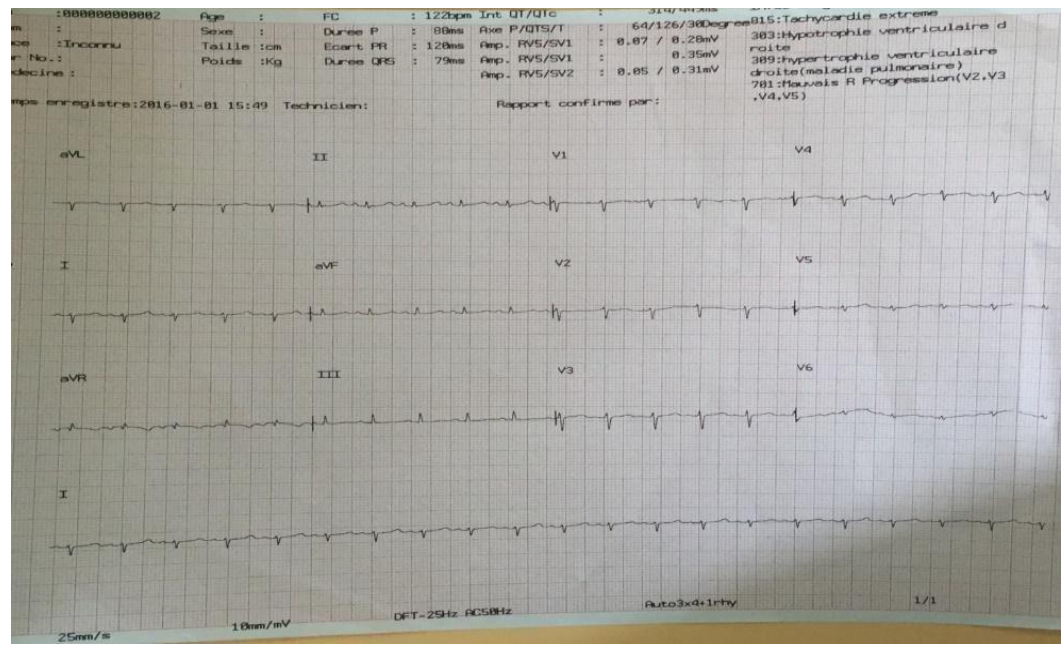

Fig-1: Electrocardiogram showing sinus tachycardia at $130 \mathrm{bpm}$ with diffuse low voltage and electrical alternans

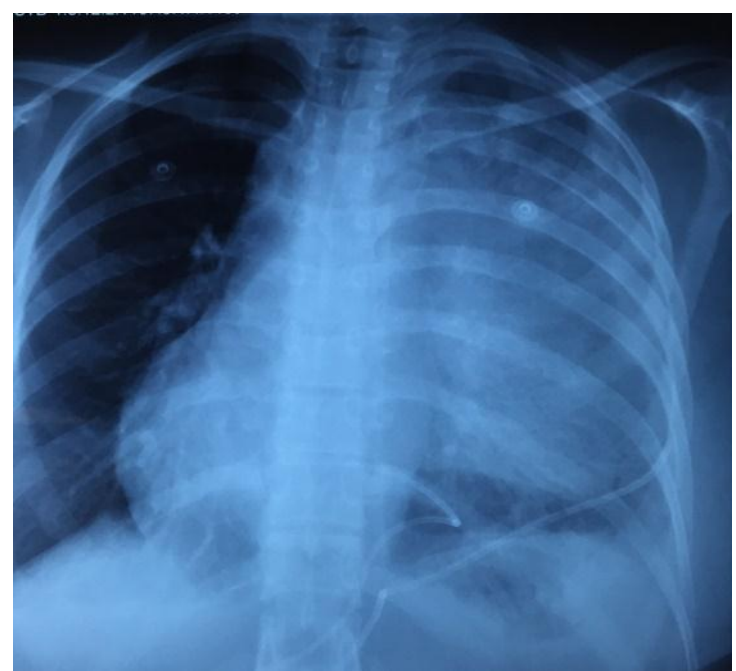

Fig-2: Chest X ray showing a "white-out" of the lung
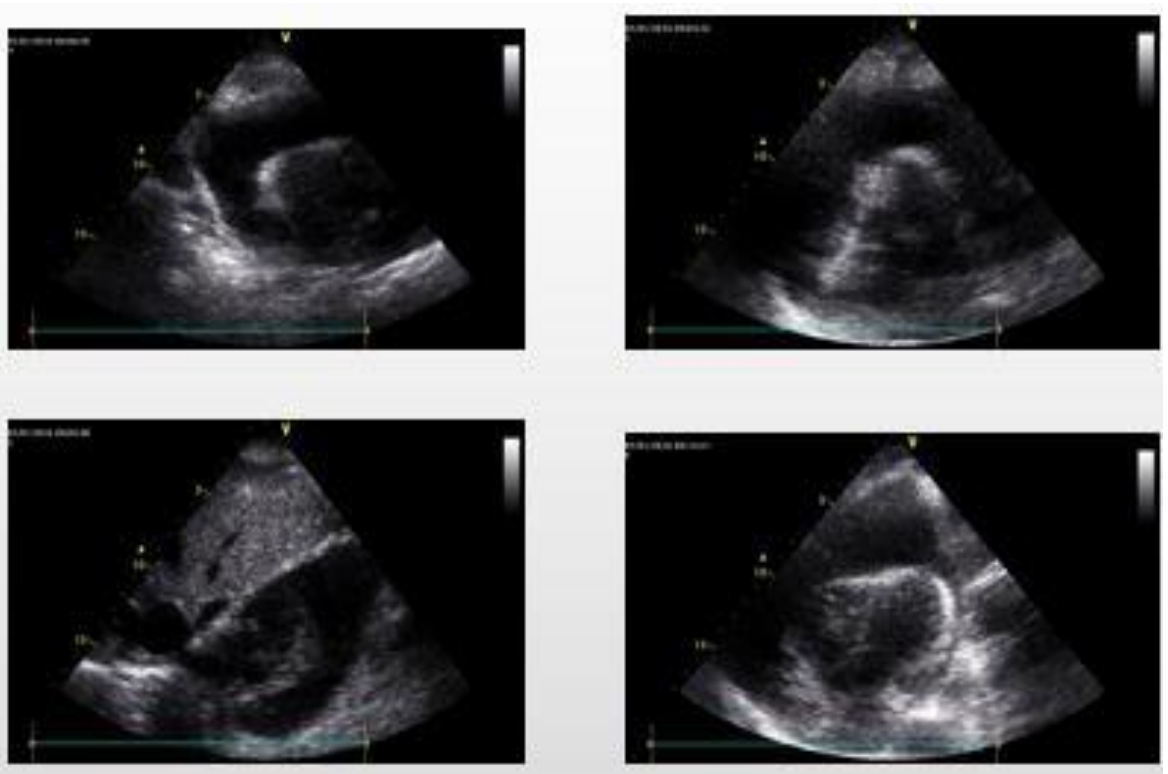

Fig-3: Transthoracic Echocardiogram showed heart surrounded by a very large pericardial effusion with features of tamponade including severe collapse of the right ventricle and dilated IVC 


\section{DISCUSSION}

Primary mediastinal (thymic) large B-cell lymphoma (PMBCL) is a subtype of diffuse large Bcell lymphoma (DLBCL) arising in the thymus. It accounts for approximately $5 \%$ of non-Hodgkin lymphomas. [1-3] First described in the 1980s [4] as occurring in younger adults (aged 30 to 40 years) with a female predominance [1-4].

On the other hand, insidious pericardial effusion of small abundance occurs in almost $40 \%$ of pregnant women during their third trimester of pregnancy. It is mainly due to viral or autoimmune disease; rarely do we find a neoplastic etiology. However, inaugural presentation or evolution to cardiac tamponade is more rare, exceptional even [5-7]. Mediastinal lymphoma may produce a pericardial effusion, but rarely presents as cardiac tamponade [7]. The association of all those conditions: pregnancy, lymphoma, in a cardiac tamponade context, made all the authenticity of this case.

In fact, cardiac tamponade is a medical emergency of which clinical features are classically an elevated venous pressure, decreased systemic arterial pressure and a quiet heart, as described in Beck's paper many years ago [8].

However, in another study of 56 patients it has been shown that this triad is often incomplete. The major symptoms are dyspnea to breathlessness, not to mention tachypnoea, tachycardia, pericardial rub and pulsus paradoxus [9].

ECG might show sinus tachycardia, low voltage complexes and non-specific ST segment and T wave changes due to pericarditis. Pendular swinging motion of the heart within a pericardial effusion is manifested by electrical alternans and it is characteristically seen only with a large effusion [11]. ECG must also be used to rule out other etiologies of hypotension rather than confirm the diagnosis of cardiac tamponade [9].

Echocardiography is the gold standard for the diagnosis of tamponade and its severity; it can also allow the diagnosis before the appearance of clinical signs [12]. It enables the quantification of the pericardial effusion and appreciation of signs of stability.

Tamponade can be detected initially by an abnormal septal motion, right atrial and right ventricular diastolic collapse, and reduced respiratory variation of the diameter of the inferior vena cava. TTE can also assess the distribution of the effusion [9].
Echocardiography also allows guidance of pericardiocentesis. The latter is the technique of catheter-based aspiration of pericardial fluid. It serves as a diagnostic modality via fluid analysis and a therapeutic modality especially with hemodynamic compromise [3], such as our patient's case.

After acute management of this emergency, establishing an etiological diagnosis can be problematic especially in a pregnancy condition where neoplastic pericarditis is not common. Thus, pericardial fluid cytology and pericardial/epicardial biopsy findings, CT/MRI, increased concentrations of specific tumor markers could assess the diagnosis.

The management of PMBCL involves chemotherapy and radiation. Pregnancy poses a real therapeutic dilemma, since we had limited knowledge about the risks of cytotoxic treatments on the fetal and future development of the child; risks that vary with the treatment used and the term of the pregnancy. In our case, we adopted an R-CHOP (rituximab, cyclophosphamide, doxorubicin, vincristine, and prednisone) regimen which achieves a cure rate of $82 \%$ in literature $[13,14]$.

In fact, this therapy allowed a spectacular improvement of clinical signs. The patient had received the entire chemotherapy during her pregnancy with a regular multidisciplinary follow up. Delivery was uneventful.

\section{Conclusion}

Cardiac tamponade is a life-threatening emergency. Mortality might be higher in pregnancy, requiring immediate pericardiocentesis. Neoplastic etiology is not common. This case reveals that PMBCL can expose to cardiac tamponade, that pericardiocentesis is the first line therapy and that the management of pregnant patients with hematological tumors can be very challenging.

Thus, a multidisciplinary approach including oncologists, radiologists, obstetricians, cardiologists, psychiatrists, and social services, is mandatory to optimize management.

\section{REFERENCES}

1. Hutchinson CB, Wang E. Primary mediastinal (thymic) large B-cell lymphoma: a short review with brief discussion of mediastinal gray zone lymphoma. Archives of pathology \& laboratory medicine. 2011 Mar;135(3):394-8.

2. Cazals-Hatem D, Lepage E, Brice P, Ferrant A, d'Agay MF, Baumelou E, Briere J, Blanc M, Gaulard P, Biron P, Schlaifer D. Primary mediastinal large B-cell lymphoma: A clinicopathologic study of 141 cases compared 
with 916 nonmediastinal large B-cell lymphomas, a GELA ("Groupe d'Etude des Lymphomes de l'Adulte") study. The American journal of surgical pathology. 1996 Jul 1;20(7):877-88.

3. Barth TF, Leithäuser F, Joos S, Bentz M, Möller P. Mediastinal (thymic) large B-cell lymphoma: where do we stand?. The lancet oncology. 2002 Apr 1;3(4):229-34.

4. Lichtenstein AK, Levine A, Taylor CR, Boswell W, Rossman S, Feinstein DI, Lukes RJ. Primary mediastinal lymphoma in adults. The American journal of medicine. 1980 Apr 1;68(4):509-14.

5. Ristić AD, Seferović PM, Ljubić A, Jovanović I, Ristić G, Pankuweit S, Ostojić M, Maisch B. Pericardial disease in pregnancy. Herz. 2003 May 1;28(3):209-15.

6. Montañez-Valverde RA, Olarte NI, Zablah G, Hurtado-de-Mendoza D, Colombo R. Swinging heart caused by diffuse large B-cell lymphoma. Oxford medical case reports. 2018 Sep;2018(9):omy075: 299-301.

7. Refaat MM, Katz WE. Neoplastic pericardial effusion. Clinical cardiology. 2011 Oct;34(10):593-8.
8. Beck CS. Two cardiac compression triads. Journal of the American Medical Association. 1935 Mar 2;104(9):714-6..

9. Collins D. Aetiology and management of acute cardiac tamponade. Critical care and Resuscitation. 2004 Mar;6(1):54-58.

10. Guberman BA, Fowler NO, Engel PJ, Gueron M, Allen JM. Cardiac tamponade in medical patients. Circulation. 1981 Sep;64(3):633-40.

11. Hancock EW. Cardiac Tamponade. Medical Clinical New American, 1979;63:223-237.

12. Kronzon I, Cohen ML, Winer HE. Contribution of echocardiography to the understanding of the pathophysiology of cardiac tamponade. Journal American CollCardiol, 1983;4:1180-1182.

13. Khalid S, Khalid A, Daw H, Maroo P. Management of primary mediastinal B-cell lymphoma in pregnancy. Cureus. 2018 Feb;10(2):e2215.

14. Perez CA, Amin J, Aguina LM, Cioffi-Lavina M, Santos ES. Primary mediastinal large B-cell lymphoma during pregnancy. Case reports in hematology. 2012;2012. 